\title{
A Diáspora dos Falantes de Iorubá, 1650-1865: Dimensões e Implicações
}

\section{David Eltis}

O estudo da escravidão e, de uma forma mais abrangente, do repovoamento das Américas, tem sido moldado por acadêmicos preparados para se ocuparem tanto com dados de arquivos quanto com textos. Não que uma disposição para lidar com dados numéricos gere explicações para as questões mais fundamentais que preocupam os historiadores, mas tal disposição ajuda-nos a selecionar as questôes mais relevantes para serem objetos de estudo. Embora grande parte do tópico etnicidade não se preste à análise quantitativa, o bom senso sugere que qualquer avaliação do processo de, por exemplo, crioulização, exige um certo número de informações básicas, como a quantidade de imigrantes, sua procedência e a duração do movimento de imigração.

De forma semelhante ao que ocorreu com tantos grupos migrantes, os iorubás não existiram inicialmente como um povo coeso com consciência de si mesmos. O surgimento do termo iorubá, ou termos freqüentemente associados a ele, como "Lucumi" em espanhol, e "Nagô" em português, no sentido de auto-identificação, pode não ter ocorrido até que a diáspora dos iorubás estivesse bem avançada - talvez até bem tarde no século dezenove. Nenhuma unidade política única jamais abrangeu os falantes de iorubá e sua exportação para o atlântico jamais esteve concentrada em um único porto de embarque escravista na África Ocidental. Temse afirmado que os iorubás somente se identificaram como tal como resultado de suas experiências no Novo Mundo ${ }^{1}$, embora pareça mais provável que a identificação com o termo tenha se desenvolvido em ambos os lados do Atlântico ao mesmo tempo, em resposta a pressões semelhantes. A queda de Oió no Velho Mundo desencadeou fugas e migrações em grande escala e isso resultou na aproximação, em novos ambientes, de fragmentos de muitos grupos distintos de falantes de iorubá, aproximação essa que incluiu muitos não-falantes. Esse rompimento no Velho Mundo 
deve ter reproduzido bem de perto as condições criadas no Novo Mundo pelo tráfico de escravos. Circunstâncias como essas tendem a acelerar a constante renovação da formação identitária, que é uma característica de todas as culturas. A resposta inicial ao trauma social da migração foi provavelmente a procura de grupos semelhantes, bem como uma redefinição de identidade social, com base nos elementos partilhados entre eles, especialmente a língua ou a religião. A analogia mais bem documentada está talvez na Europa, ao invés da África, no que se refere à situação de emigrantes de fala alemã do século dezoito, tanto para as Américas quanto para a Europa Oriental. Sem unidade política em sua terra natal, os migrantes não se consideravam alemães, mas sim habitantes da região do Reno, ou suíços, ou ainda prussianos. A emigração reformulou radicalmente as percepções do grupo sobre si mesmo e seus descendentes, mas não a ponto de se identificarem como cidadãos britânicos, americanos ou russos. No início, a migração os fez alemães, tanto aos seus próprios olhos, quanto aos dos outros. ${ }^{2}$

Os iorubás têm uma visibilidade tão acentuada no movimento forçado dos povos da África para as Américas que surpreende o fato de que muito pouco tenha sido realizado no sentido de se efetuar um levantamento adequado de dados numéricos pertinentes. Se essa é a situação referente a um grupo tão bem conhecido, a situação de outros grupos certamente não pode ser melhor . No mínimo, a literatura sobre a diáspora africana se debruça mais sobre suas origens geográficas, nas regiões costeiras, do que sobre a forma como aqueles surpreendidos pelo tráfico escravagista se identificavam. Nosso conhecimento, neste momento, é muito limitado a amplas tendências geográficas. Em relação à Baía de Benin, o desvio para o leste do fluxo dos africanos que foram entregues ao tráfico internacional de escravos é bem conhecido, mas a abrangência e o ritmo dessa mudança permanecem desconhecidos. Porque os iorubás moravam no leste, pressupõe-se que eles se viram gradativamente afetados pelo tráfico. Os africanistas começaram a fazer estimativas sistemáticas preliminares da posição das nações africanas na migração forçada, mas essas estimativas estão aquém do que foi obtido em relação aos imigrantes europeus que partiram voluntariamente da Europa. Gostaria de tentar fazer aqui uma estimativa mais sistemática do envolvimento dos iorubás, bem como 
explorar as implicações dessas descobertas para iluminar questões mais amplas do repovoamento das Américas.

A avaliação de tal processo exige, de fato, uma noção da dimensão e direção dos movimentos dos povos. Como David Richardson, Stephen Behrendt e eu mesmo explicamos, em mais detalhe, em outras pesquisas e publicações, o método básico de estimar as partidas dos escravos para a costa da África é utilizar estimativas qüinqüenais (ou de períodos maiores quando os dados qüinqüenais não estiverem disponíveis) da participação nacional do tráfico e distribuí-los pelas oito regiōes costeiras da África, de acordo com o registro de atividade escravagista em The Translatlantic Slave Trade: A Database on CD-ROM, contendo mais de $27.000^{3}$ viagens. Alguns falantes de iorubá partiram da África por portos da Baía Ocidental de Biafra, como Rio Brass e Bonny, mas a grande maioria embarcou em portos localizados na Baía de Benin. A Baía de Benin é considerada aqui como abrangendo desde a costa do Rio Volta até o Rio Nun. ${ }^{4} \mathrm{O}$ tráfico de escravos nas costas da África Ocidental e Centro-Ocidental foi sempre dominado por poucos pontos de embarque. Com exceção da Costa Windward, o tráfico de escravos não se formou a partir de um comércio costeiro extensivo realizado por navios negreiros antes de partirem para as Américas [N. do T: viagem conhecida, em inglês, como middle passage, já que era a segunda fase de uma viagem de três partes: Europa-África, ÀfricaAméricas e Américas-Europa.] Desde o início, tanto os navios quanto os comerciantes africanos parecem ter concentrado as suas atividades à volta de uns poucos portos de cada região, embora a identificação desses portos tenha aos poucos mudado com o passar do tempo. O Congo, o Velho Calabar, Ajudá e o Rio Gâmbia parecem ter dominado suas respectivas regiōes desde o início. $\mathrm{O}$ tráfico se expandiu pela adição de novos portos, ou por meio da substituição dos portos antigos.

Os padrōes do comércio dentro da África estão muito menos bem documentados do que outras atividades de transporte marítimo, embora todos os indícios sugiram que, em geral, os escravos viessem para a costa pela rota mais direta. Nas terras interioranas da Costa do Ouro (Gold Coast), bem como nas Baías de Benin e de Biafra, era pouco comum haver comércio de grande escala do leste para o oeste. Era também incomum haver um movimento de escravos destinados aos mercados do 
Atlântico, especialmente cruzando fronteiras étnicas importantes, pelo menos na ausência de uma rota fluvial conveniente, como o Alto Níger. As rotas de comércio dentro da África se mostraram flexíveis e adaptáveis, por razões de guerras e mudanças políticas; mas é razoável procurar grupos lingüísticos importantes partindo dos portos mais próximos ao ponto onde eles foram capturados e destinados ao tráfico transatlântico.

Isso é ilustrado por uma notável série de documentos nos registros da Corte Anglo-Espanhola da Comissão Mista que se reuniu em Havana, entre 1821 e 1845 . Assim como outras Cortes situadas em volta das bacias atlânticas, a Corte abjudicava navios negreiros capturados por signatários (entre os quais, sempre a Grã-Bretanha) de tratados bilaterais. Na fase final de sua vigência, os tratados autorizavam as cortes a condenarem e destruírem as embarcaçōes de escravos e seus conteúdos, além de formalmente libertar quaisquer escravos encontrados a bordo. Por insistência dos britânicos, havia grande cuidado em identificar tais escravos libertados, porque eles deveriam ser soltos em sociedades onde a pele negra era condição suficiente para escravizar (ou reescravizar) um homem. Para assegurar uma base permanente de identificação de escravos libertados, cada corte mantinha duas cópias de um registro de indivíduos libertados, um dos quais era enviado a Londres. ${ }^{5}$ Da mesma forma que os registros mantidos nas cortes de comissão mistas de Serra Leoa (a maioria deles ainda existentes), os registros continham o nome, idade e o lugar de moradia de cada africano incluído na jurisdição da corte. A corte adicionava a altura e o sexo da pessoa, uma descrição do mais óbvio sinal físico e, logicamente, o nome da embarcação que carregava os escravos recapturados da África. ${ }^{6}$ Em mais do que noventa e nove por cento dos casos, o nome constante do livro de registros é claramente africano e se constitui em uma das poucas fontes pré-coloniais existentes de nomes africanos. ${ }^{7}$ Toda a informação parece ter sido mediada por intérpretes africanos da mesma parte da costa em que a embarcação apreendida havia embarcado os escravos, cuja identidade era adicionada ao livro de registros. Ao contrário do caso de Serra Leoa, onde a prática de registrar o lugar de moradia foi interrompida após alguns anos, a coluna "país" foi preenchida durante todo o período em que funcionou a corte. Os livros de registro contêm o nome africano e o país de 10.390 pessoas e esses dois dados dão uma base para identificar a 
região de origem de cada pessoa recapturada, sem a necessidade de adotar as problemáticas idenficações de etnicidade, inspiradas nos europeus, que dificultaram as tentativas de determinar as terras de origem dos africanos nas Américas. ${ }^{8}$ Além disso, a informação nos livros de registro podem ser comparadas com o que se sabe sobre o porto de embarque africano de cada uma das 41 embarcações que a corte adjucou. Cada uma dessas embarcaçóes pode ser encontrada na base de dados publicada recentemente sobre o comércio de escravos transatlântico e, em todos os casos, o ponto de origem da costa africana dos navios negreiros é claro. ${ }^{?}$

A tabela 1 mostra uma relação preliminar das designações étnicas que a corte deu aos 3.663 homens, mulheres e crianças da Baía de Benin nesses anos. Para os espanhóis nessa época, parece que o termo "Lucumi" não era sinônimo de iorubá, apesar de alguns estudiosos acharem que sim. As extensões do termo "Lucumi" na tabela indicam que os cubanos aplicavam essa designação geral a muitos não iorubás. Além disso, alguns africanos libertados que saíram de portos fora da Baía de Benin, embora adjacentes à mesma, são também descritos como Lucumi, enquanto que outros, partindo dos portos situados mais a leste na Baía de Benin, eram identificados como Carabali. Dessa forma, os cubanos não utilizavam o termo Lucumi nem para caracterizar alguém que era forçado a embarcar na viagem da Àfrica para as Américas de um porto na Baía de Benin, nem alguém que se identificasse a si mesmo, ou a si mesma, como iorubá. A melhor definição de termos abrangentes regionais como Lucumi, Carabali, bem como Congo e Ganga, recorrentes nos registros da Corte, é uma definição geográfica. Lucumis são aqueles que vivem na região interiorana correspondente à Baía de Benin; Carabalis são seus semelhantes que vivem atrás dos principais portos da Baía de Biafra; e Congos são aqueles da África Central Atlântica, enquanto que os Gangas habitam uma ampla região interiorana da Alta Guiné.

Designações tão amplas claramente não são muito úteis para pesquisadores modernos interessados nas naçōes ou etnicidades daqueles forçados a passar pela middle passage, mas a tabela 1 também mostra que a maioria dessas designaçóes era qualificada por uma extensão que era muito mais específica e que, para a maioria dos escravos, pode estar ligada a nações conhecidas dos pesquisadores modernos. Identificações experimen- 
tais desses termos sugerem que 62.5 por cento, ou a maioria absoluta daqueles que partiam da Baía de Benin, se viam como iorubás. Aqueles países que não podem ser identificados eram em pequeno número. ${ }^{10} \mathrm{Como}$ não parece haver nenhuma razão específica pela qual a marinha britânica tenha prendido mais escravos de uma etnia do que de outra, ${ }^{11}$ não há tendência na amostragem que aparece na tabela 1 e as proporçôes de nomes de países nela indicadas poderiam ser consideradas referentes aos anos de 1826-39 como um todo. A aplicação das proporções para o volume de migração forçada partindo da Baía de Benin, nesses mesmos anos, nos leva a uma estimativa da partida de escravos iorubás durante esse período de quatorze anos de 101.750, ou 7.200 por ano. ${ }^{12}$

Para a época anterior a 1826, torna-se necessária uma aproximação diferente que leva em consideração as amplas tendências históricas dentro da África, além de dados detalhados das partidas de portos específicos. Um passo preliminar na análise é o estabelecimento da proposição já feita de que migrantes forçados de uma nação africana específica teriam a tendência de partir do porto mais próximo de onde a nação estava localizada. A Tabela 2 mostra os dados espanhóis sobre etnicidade, distribuídos por portos, dentro da Baía de Benin, onde indivíduos embarcaram se dizendo pertencentes àquela nação. Os quadros correspondem, de uma forma geral, à região ocidental da costa - Popo, a região central do litoral, Ajudá e a região oriental (Badagri e Lagos). Como era de se esperar, a proporção de iorubás embarcados aumentou, à medida que examinamos os portos do oeste para o leste. No leste, a maioria absoluta dos africanos recapturados se auto-intitulava iorubá. Não há razão para se crer que esse padrão não estivesse já estabelecido bem antes da segunda década de 1800 . Na ausência de qualquer impedimento duradouro, de natureza política ou militar, para o embarque de escravos em Lagos ou Badagri, é razoável pressupor que os falantes de iorubá teriam formado, na melhor das hipóteses, uma minoria entre aqueles levados a bordo nos portos ocidentais no período anterior. Dito de uma outra forma, se grandes números de falantes de iorubá tivessem sido enviados às Américas antes, digamos, da queda do Império Oió, na última parte do século dezoito, esperar-se-ia que Lagos e Badagri emergissem como os grandes condutores desse movimento. Para os proprietários de escravos na África e nas Américas, bem como durante 
uma middle passage cheia de revoltas, escravos adultos homens, conquanto valiosos, eram potencialmente problemáticos e caros quando em trânsito. Uma rota direta entre a primeira venda ou prisão e o local de embarque era essencial para manter os ganhos. A maioria das narrativas dos escravos que indicam uma rota lenta e sinuosa para a costa é baseada nas experiência das crianças, mais fáceis de controlar. $\mathrm{O}$ passo seguinte para estabelecer uma estimativa da presença de falantes de iorubá na era pré1820 é distribuir as partidas dos escravos da Baía de Benin em um determinado período de tempo. Felizmente, tanto a data das partidas dos escravos, como os padrões da história pré-colonial da Costa dos Escravos essencialmente a Baía de Benin - são os mais bem documentados de todas as regiōes que contribuíram com grandes números de escravos para as Américas. A Tabela 3 mostra a distribuição por portos, estimada diretamente de uma versão atualizada da base de dados do CD-ROM. Ela mostra, primeiramente, uma grande preponderância de portos ocidentais e centrais da Costa dos Escravos no envio de cativos para as Américas no século dezessete e na primeira parte do século dezoito. Acima de tudo, é claro, a tabela mostra a extraordinária primazia de Ajudá no primeiro quarto do século dezoito, pouco antes da conquista de Dahomé. Esta primazia não se deu somente na Baía de Benin, mas provavelmente ocorreu em toda a costa da África onde, por um tempo, Ajudá deteve o mais alto número de embarques para um único porto. No período imediatamente posterior à conquista, os portos imediatamente a leste de Ajudá - primeiramente Epe e depois Badagri - foram incluídos no tráfico, mas Popo, no oeste, também o foi, embora antes dessa época certamente houve tráfico de escravos da costa, desses portos para Ajudá. Partidas diretas de escravos de Epe começaram por volta de 1737, mas na segunda e terceira quartas partes do século dezoito essa mudança inicial em direção ao leste, afastando-se de Ajudá, foi modesta, servindo para preencher o vazio deixado pela destruição que Dahomé impingiu a Jaquim em 1732, ao invés de substituir Ajudá. Epe e Badagri, juntos, embarcaram menos de um terço do número de escravos que saíram de Ajudá entre 1726 e 1750, enquanto que as partidas de Popo alcançaram tão-somente um quinto das de Ajudá.

A tabela 4 mostra estimativas qüinqüenais das partidas de escravos para o período crítico de transição, 1751-1800, durante o qual Porto Novo 
ultrapassou Ajudá como o porto escravagista mais importante. A característica principal dessa metade de século foi a luta entre Dahomé e os portos orientais por escravos originários do interior e do leste de Dahomé, em verdade tão a leste quanto Benin. Epe foi, no começo, o porto oriental mais importante. Como Badagri, o comércio era mais freqüente com os franceses e era suscetível à diminuição das partidas de escravos em função das guerras européias. Benin foi menos afetada pelas guerras no Atlântico por servir, de uma maneira geral, aos vitoriosos ingleses, esporadicamente a partir da segunda década de 1700, e regularmente a partir de 1755, embora muitos desses prisioneiros não viessem de Benin propriamente, dita, mas sim de outras regiōes administrativas onde predominavam os falantes de Edo e de Itsekiri. ${ }^{13}$ Por quinze anos depois de 1755, Benin foi o mais importante ponto de partida da parte oriental da Baía de Benin. Isso não indica necessariamente um aumento no comércio de escravos, já que alguns desses cativos, sem dúvida, teriam saído, em um período anterior, via Ajudá, Epe ou Badagri. Além disso, mesmo sem escravos de Benin (e menos ainda de Oió), Ajudá ainda enviava entre duas e três vezes mais escravos para as Américas naqueles anos do que Benin. Badagri ultrapassou Benin por um breve período, depois de 1770 , como um ponto de contato direto com os europeus, talvez ajudado por menos impostos alfandegários para comerciantes, tanto africanos como europeus. No entanto, a instabilidade política no sistema distrital de Badagri logo interferiu no comércio e, quando Oió retirou sua proteção de Badagri, Dahomé formou uma aliança com outros portos orientais e lançou uma série de ataques que culminaram com a destruição tanto de Epe quanto de Badagri. ${ }^{14}$ Mas Porto Novo, e não Dahomé, surgiu como o principal beneficiário dessa aliança, enviando mais escravos do que qualquer outro porto da Costa dos Escravos no último quarto do século dezoito. É surpreendente como as estimativas qüinqüenais das partidas de escravos estão de acordo com o que se sabe da atividade política e militar desse período - derivadas tanto de tradiçôes orais africanas como de relatos europeus. A dominação de Porto Novo não durou muito. As partidas de Lagos aumentaram de quatro a cinco vezes entre o último quarto do século dezoito e o primeiro quarto do século dezenove. Havia poucos sinais, no final do século dezoito, de que o papel de Lagos viesse a se tornar preponderante 
nos embarques da Costa dos Escravos do século dezenove. ${ }^{15}$ Cerca de mil escravos por ano partiam, por volta de 1790, e comerciantes de escravos britânicos quase duplicaram essa média anual nos poucos anos que antecederam a 1807. Mas a maior responsável pela quadruplicação das partidas anuais, entre 1801 e 1825 , foram as atividades dos comerciantes de escravos portugueses, principalmente levando escravos para a Bahia. O tamanho da amostragem em que se baseiam as estimativas para 18011825, na Tabela 3, é pequeno, pelos padrões usuais do conjunto de dados, embora adequado (o porto exato de embarque só é conhecido para um quinto dos escravos que se estimou terem saído), e é possível que a estimativa para Lagos seja alta demais; mas o aumento das partidas de escravos no começo do século dezenove deve ter sido substancial. À medida que o comércio transatlântico de escravos se aproximou do fim, Lagos e Ajudá enviaram, juntos, noventa por cento de todas as pessoas que faziam parte do comércio escravagista transatlântico da Costa dos Escravos, com Lagos sendo responsável por sessenta por cento, antes do ataque britânico e a consequiente ocupação da ilha, em 1851, dezesseis anos antes que o resto do tráfico escravagista transatlântico tivesse terminado. Sua súbita retirada do tráfico, como resultado do ataque britânico, restabeleceu Ajudá a seu velho papel de principal - em verdade, por vezes único - porto de embarque da Costa dos Escravos.

A primazia tardia de Lagos no tráfico escravagista foi causada em parte pela política e em parte por sua localização. Como no século precedente, Ajudá era um mercado menos atraente para comerciantes escravagistas de fora de Dahomé do que Lagos e Porto Novo. A evolução da comunidade mercantil escravagista de Dahomé, autônoma em relação à autoridade real, está agora afirmada. Um número menor de exportados foi preso pelas forças de Dahomé, ou escravizados dentro de Dahomé na quarta década de 1800 do que um século antes. Mesmo assim, o controle do estado permaneceu e as cidades-estado do leste não somente compravam todos os escravos postos à venda, mas também davam oportunidade aos estrangeiros para comercializarem por sua própria conta. Muitos representantes de firmas baseadas no Brasil, originários da comunidade afroportuguesa, continuaram a fazer negócios em Lagos. ${ }^{16}$ Este também era mais próximo da maior fonte de escravos do que quaisquer outros portos 
da época, já que a queda do Império Oió provavelmente gerou a maior parte dos escravos que embarcaram para as Américas provenientes da Costa dos Escravos depois de 1825. Além disso, Lagos também era mais suscetível a um ataque direto do mar do que qualquer outro grande porto. $\mathrm{O}$ sistema de lagoas fazia com que os escravos pudessem ser levados rapidamente a pontos de embarque que estavam fora do conhecimento dos barcos patrulheiros, o que foi uma das razões pelas quais o tráfico de escravos durou mais tempo aqui do que em qualquer outro lugar. Mas, em forte contraste com Ajudá e Porto Novo, as embarcações podiam bombardear as instalações que serviam ao tráfico de escravos em Lagos, bem como manter uma ocupação com menos custos do que seriam necessários para uma operação semelhante contra quase qualquer outro grande centro de deportação de escravos da costa oeste da África. Foram necessários dois ataques britânicos antes que Lagos fosse ocupado, mas a ocupação foi possível e pôs fim ao tráfico imediatamente.

O terceiro passo na atribuição de uma estimativa das partidas de falantes de iorubá é a ligação de portos específicos com as "nações" africanas. Não temos nada parecido com os dados disponíveis aos espanhóis para calcular os números de iorubás antes da segunda década de 1800. Em verdade, como já foi observado, pode ser que o que esteja sendo medido tenha a ver com falantes de iorubá, ao invés de um grupo iorubá consciente de si-próprio. Uma primeira solução é nos basearmos em uma discussão anterior da relação entre o local das principais nações africanas e os portos de embarque. A Tabela 2 mostra os iorubás embarcando em portos localizados mais perto de sua terra natal. Já que este parece ter sido um fenômeno universal dos povos do Velho Mundo que migravam para o Novo Mundo, quer os imigrantes fossem obrigados a embarcar ou o fizessem de forma voluntária, não seria interessante aplicarmos as razões de etnicidade dos portos, da Tabela 2, para toda a era pré-1820? Para fazer isso, cumpre primeiramente agrupar os pontos de embarque vistos na Tabela 3 às regiōes do oeste (Grande e Pequeno Popo), central (Ajudá, Ofra, Epe, Porto Novo) e do leste (Badagri, Lagos, Benin). A porcentagem de escravos que eram iorubá, mostrada na coluna 8 da tabela 2 , é atribuída a esses três grupos para todo o período. Essas proporçôes são usadas então para converter as estimativas de partidas como um todo (tomando os nú- 
meros somados das exportações dos portos que compõem cada grupo da tabela 3) em estimativas referentes tão-somente à partida dos iorubás. A estimativa resultante do tamanho da diáspora dos falantes de iorubá é, assim, uma função de, em primeiro lugar, uma amostragem detalhada da etnicidade de um período de 14 anos no século dezenove e, em segundo lugar, uma distribuição de partidas de escravos de agrupamentos de portos da Costa dos Escravos por períodos de 25 anos, entre 1651 e 1867. Este procedimento resulta em um total para a diáspora de falantes de iorubá, pelo período de 217 anos, de 1,67 milhão. ${ }^{17}$

Parecerá à maioria dos historiadores excessivamente mecânico deixar a estimativa, nesta primeira avaliação, dependente, como está, de uma distribuição ocorrida no século dezenove. $\mathrm{O}$ que fontes qualitativas podem ajudar a esse respeito? A etnicidade dos escravos partindo da Baía de Benin é menos bem conhecida do que as lutas militares e políticas entre comunidades costeiras que levaram a exportação desses presos, e a visão geral da procedência escravagista na Baía de Benin aqui proposta resume, antes de acrescentar alguma novidade, o que já é sabido. Três grandes fases podem ser percebidas nos dois séculos depois de 1650. A primeira vai até cerca de 1725, a segunda vai da conquista de Ajudá ao surgimento de Lagos como um porto dominante, por volta de 1800 , e a terceira vai de 1800 até o fim do tráfico escravagista.

Uma expansão extremamente rápida do comércio escravagista ocorreu no primeiro período, levando a números jamais alcançados (ao menos em relação à Baía de Benin) no período de 1701-1725. O tráfico se afunilava por Ajudá, Popo e Ofra, portos que, se não eram "livres" no sentido europeu atual, certamente atraíam vendedores de escravos de oitenta milhas ou mais do interior. Escravos Lucumi (incluindo tanto escravos iorubás como não-iorubás) aparecem no começo do século dezoito em Cuba (um mercado bem menor para escravos neste período), mas não há indícios de um forte componente de fala iorubá nesta primeira fase do tráfico. O Caribe Britânico foi o primeiro grande mercado para a Costa dos Escravos, entre 1670 e 1714, quando o tráfico escravagista chegou ao seu ápice na região. As extensas fontes primárias sobre o comércio britânico para esses anos mencionam muitos povos africanos, mas não conheço nenhuma que identifique escravos como iorubás, ou os povos que even- 
tualmente se incluíram nessa denominação. As referências muito ocasionais a grupos chamados de Lucumi, nos registros das Américas, bem como as baixas porcentagens deste mesmo grupo entre os escravos da Costa dos Escravos, segundo os estudiosos da costa africana sugerem, indicam que eles constituíam não mais do que doze por cento das partidas da Baía de Benin. Como nem todos os Lucumi eram falantes de iorubá, a proporção de iorubás teria sido menor. ${ }^{18}$

Os acontecimentos no Dahomé fizeram com que grande parte dos escravos saíssem através da Baía de Benin naquela época, mas a ausência de iorubás sugere que a expansão militar de Dahomé deu-se para o norte, em vez de para o leste, com a agitação política decorrente da queda do império Akwamu no oeste, assim como das atividades no oeste e em Oió, que resultaram em números muito menores. A grande maioria dos escravos enviados para as Américas devem ter sido Ewes, Adjas, Hueas ou Fons. ${ }^{19}$

A segunda fase abrangeu o período de relativo declínio de Ajudá, do final da década de 1720 até sua substituição por Lagos como o primeiro centro de exportação do Atlântico, no começo do século dezenove. As ações do Dahomé contra os rivais baseados em Lagos no negócio de exportação de escravos resultou em captura de mais cativos e mudou a saída do tráfico dos escravos mais para o sul - para mais perto da costa, enquanto que a tentativa do Dahomé de exercer um papel intermediário e de conseguir escravos de fora do Dahomé teria, comercialmente, em parte, compensado essa mudança do tráfico para o sul. Os portos orientais que surgiram nessa fase atraíram escravos principalmente de falantes de iorubá no leste, afetados pelas atividades de Oió, em vez de seu principal rival no oeste, Dahomé. A maioria dos escravos Epe/Badagari se originou em Oió, no norte e leste longínquos, o que constituiu mudança no fluxo que anteriormente passava por Ajudá e que era composto, provavelmente, sobretudo por falantes de iorubá. ${ }^{20}$ Mas Badagri e Lagos, juntos, eram responsáveis por somente quinze por cento de todos os exportados da Baía de Benin na segunda metade do século dezoito. Poder-se-ia supor que houvesse uma mistura de falantes Ewe, Fon e Gbe, bem como povos iorubá, com um fluxo menor de escravos prisioneiros originários da região etnicamente diversa do delta do Níger, passando por Benin. 
$\mathrm{Na}$ terceira fase das partidas dos escravos, o equilíbrio entre falantes de iorubá e prisioneiros Ewe-Fon-Gbe oscilou fortemente em direção aos primeiros. Como observado, o papel intermediário de Ajudá aumentou no século dezenove, com mais escravos se originando fora das fronteiras do Dahomé. Que esses escravos se originassem, em sua maioria, do nordeste é sugerido pelo fato de que, depois de 1810, mais da metade dos escravos saídos da Costa dos Escravos para as Américas aportou na Bahia. Tradições iorubá e, em menor número, Hausa, mas não Ewe-Fon, dominaram as comunidades de escravos do século dezenove na Bahia. Por outro lado, no final do século dezoito em St. Domengue (colônia que também se abastecia de Ajudá), os iorubás eram quase tão numerosos como os Ewe-Fon. Tomando como base 221 inventários de escravos na região da Bahia entre 1737 e 1841, Verger notou a quase total ausência dos nagoiorubás até o começo do século dezenove, e sua presença maciça por volta de 1830 ... os escravos originários do Dahomé estavam presentes desde o começo... Depois de 1851 e do término do comércio escravagista para o Brasil e para Lagos, Ajudá parece, paradoxalmente, ter aumentado sua área de captura, pois escravos que iriam passar por Bonny eram agora embarcados na Costa dos Escravos, mas os números nesses últimos anos era de somente 2.000 por ano em média, comparados a 11.000 no período de $1826-50 .{ }^{21}$

Uma estimativa mínima de partidas de falantes de iorubá é obtida se dividirmos a totalidade do comércio escravagista tendo por base o ano de 1800. Antes deste ano, poderíamos pressupor que somente dez por cento de todos aqueles forçados a sair da Baía de Benin eram iorubás, enquanto que em relação ao século dezenove poderíamos aceitar os indícios de $\mathrm{Ha}$ vana, reforçados pelo julgamento de Verger baseado nos inventários das plantaçôes baianas, que atribui um maciço crescimento nas chegadas dos iorubás depois de 1800, após níveis bem baixos anteriores a este ano. Dez por cento dos totais anteriores a 1800, na última coluna da tabela 3, é de 147,6 mil, e a parte pós-1800 do total dos falantes de iorubá estimada anteriormente é de 499,4 mil. A estimativa total de partidas dos iorubás para todo o período é, assim, de 647.000 (ver nota 17).

A diferença entre as estimativas máximas e mínimas, de 1,67 milhão de iorubás contra 650 mil, é demasiadamente grande, mas a discussão precedente e as novas estimativas das partidas de escravos da Baía de Benin 
ao menos nos permitem concentrar no que precisamos saber e quais outras conjecturas podem eventualmente ser admitidas. Resumindo, sabemos que relativamente poucos iorubás (ou aqueles que vieram mais tarde a ser chamados de iorubás) partiram para as Américas antes da conquista de Ajudá - provavelmente não mais do que dez por cento de todos os que partiram da Baía de Benin. A estimativa superior está certamente equivocada em sua assunção de que quatro de cada cinco exportados de Ajudá e Ofra eram falantes de iorubá antes de 1726 . No outro extremo do espectro temos a amostragem de Havana, sugerindo que quase nove de dez dos que foram obrigados a embarcar na Baía de Benin depois de 1800 eram iorubás, no sentido amplo do termo. Entre 1725 e 1800 e, de fato, em qualquer período anterior a 1800 , podemos afirmar que quase nenhum dos escravos que partiram dos portos do oeste da Baía de Benin eram falantes de iorubá. Pontos de embarque a leste, como Badagri e Lagos, por outro lado, devem ter embarcado principalmente falantes de iorubá, mas entre 1726 e 1800 esses portos enviaram somente cerca de 93.000 escravos para o tráfico - ou pouco mais de mil por ano - e nenhum antes de 1726. ${ }^{22}$ A região mais problemática, e a principal razão da ampla diferença entre a maior e a menor estimativas são os portos centrais da Baía de Benin, especialmente Ajudá, durante os últimos setenta e cinco anos do século dezoito. Não pode haver certeza, até agora, sobre como as quase 600.000 pessoas que embarcaram nesses portos se identificavam.

Ainda assim, algumas suposições adicionais, geralmente coerentes em relação a tendências apresentadas pela literatura, permitem a elaboração de uma terceira estimativa de partidas. Em relação aos portos centrais, parece razoável estimar que tenha havido um gradual, embora progressivamente mais rápido, aumento de exportados falantes de iorubá, à medida que o tempo se passava, entre 1720 e o começo do século dezenove, com a maior parte desse aumento ocorrendo tardiamente no período, como resultado da desordem originada pelo declínio do Império Oió. Assim, pressupomos um aumento na exportação de iorubás (a partir de $10 \%$ em 1700-1725) de 16 pontos precentuais em cada um dos seguintes periódos de 25 anos, indo para $26 \%$ no período de $1726-50$, 42\% no período de 1751-75 e para 58\% no período de 1776-1800. Após 1800, pressupomos um aumento mais substantivo (ocasionado pelo declínio de 
Oió e em conformidade com os dados de Havana), para $81 \%$. No que tange aos números relativamente pequenos de escravos que deixaram os portos ocidentais antes de $1800,5 \%$ de iorubás parece representar uma proporção razoável, enquanto que para os portos ocidentais a razão usada no primeiro conjunto de estimativas, de $98,9 \%$ de iorubás, se mantém. Essas conclusões geraram as estimativas apresentadas na coluna 1 da tabela 5 e constituem as séries mais aceitáveis. Uma migração total de falantes de iorubá da ordem de 968.000 foi obtida, dois terços dos quais partiram para as Américas entre 1776 e 1850, com os picos ocorrendo entre 1826 e $1850 .{ }^{23}$

A tabela 5 também mostra a distribuição estimada dos totais referentes a essas quartas partes de século, pelos destinos finais dos escravos nas Américas. O método usado para derivar essa série é descrito de forma mais completa em outro lugar. Resumidamente, a base de dados transatlântica reformulada fornece o destino americano para 849.000 escravos que saíram da Baía de Benin entre 1651 e 1865, de um total projetado de pouco mais de dois milhóes de partidas. Este número, alto, oferece a base para que se possa fazer uma estimativa dos destinos que faltantes, embora os leitores devessem ter em mente que neste exato momento não tentamos separar destinos de iorubá de destinos de não-iorubá. ${ }^{24}$ Com uma média de mortalidade na viagem da África para as Américas de cerca de 13,4 por cento (baseada em 756 viagens originárias da Baía de Benin), os dados na tabela 5 não devem ser confundidos com chegadas. Talvez somente 831 mil sobreviventes tenham desembarcado nas Américas e em Serra Leoa. É desnecessário enfatizar o caráter aproximativo desse resultado. A proporção de falantes de iorubá entre os exportados, no período de 1726 a 1800, pode muito bem ter seguido uma curva mais dramática do que aquela usada para fazer a tabela 5 . Há quase certeza de que essa primeira tentativa de reconstruir uma diáspora para um grupo de língua africana (e eventualmente também para um grupo étnico) será melhorada no futuro, na medida em que mais informaçōes se tornem disponíveis.

A tabela mostra uma diáspora muito disseminada. Os falantes de iorubá perfazem menos de nove por cento dos africanos levados ao Novo Mundo, mas eles foram exportados para a maioria dos lugares das Américas, de Chesapeake, no norte, até o Rio da Prata, no sul. Nenhum outro grupo migrante europeu alcançou tantas partes das Américas, ou aproxi- 
mou-se, em números, dos falantes de iorubá nos cem anos anteriores a 1850. ${ }^{25}$ Mesmo assim, apesar de toda essa abrangência, bem mais do que dois terços dos iorubás deveriam ir para somente três destinos - S. Domingos, Cuba (respondendo por quase toda a coluna do Caribe Espanhol na tabela 5) e para a Bahia. Um número surpreedentemente pequeno de falantes de iorubá chegaram ao Caribe Britânico, exceto pelas pequenas antilhas Britânicas e Trinidad, no curto período de 1792-1807, entre o período de guerra do fim do tráfico francês e a abolição britânica da escravatura. Vinte mil embarcaram para a Jamaica na terceira quarta parte do século dezoito, mas tanto aqui como nas pequenas antilhas Britânicas e Trinidad eles totalizaram menos do que sete por cento de todos os africanos levados para essas ilhas nessa época. É bem provável que os falantes de iorubá não fossem o maior grupo africano levado para as Américas na época do comércio escravagista, embora fossem a grande maioria dos povos a saírem da Baía de Benin, somente em uma região específica - a Bahia - os povos iorubá constituíram dois quintos das chegadas de escravos compartivamente a todas as regiōes americanas que os receberam. ${ }^{26}$ Como mostra a tabela 5, os falantes de iorubá surgiram tardiamente no comércio escravagista. Geralmente participaram em números bem altos no tráfico somente na ocasião em que as fortes ligaçōes entre locais específicos na África e nas Ámericas, que ficaram claras no começo do tráfico, começaram a se desfazer. Cuba, em particular, tendo recebido mais do que 95 por cento de seus escravos depois de 1790, trouxe números significativos de africanos das mais diversas partes da África sub-saariana, exceto da Senegâmbia e da costa índica. Os falantes de iorubá não podem ter totalizado mais do que 12 por cento das chegadas a Cuba e certamente totalizaram menos do que 20 por cento dos que foram levados para $S$. Domingos. Na Bahia, ao contrário, é possível que eles tenham chegado a quase quarenta por cento e constituíram o maior grupo identitário. ${ }^{27}$

A discussão sobre os rumos assumidos pela diáspora dos iorubás não leva em consideração as migrações secundárias que ocorreram quando o comércio escravagista terminou. $\mathrm{O}$ movimento de vários milhares de iorubás que voltaram para suas terras natal provenientes de Serra Leoa, do Brasil e de Cuba é agora bem conhecido. ${ }^{28}$ Enquanto os iorubás parecem ter sido um povo que liderou os esforços de voltarem para a África, essa 
repatriação é provável que não tenha sido muito grande, relativamente ao fluxo migratório de saída - talvez não mais do que alguns milhares. Mais importante, numericamente, foram as mudanças de uma parte da diáspora para outra. Perto de 40.000 africanos foram levados paras o Caribe Britânico depois de 1834, principalmente para a Jamaica, Guiana Britânica e Trinidad, com provavelmente não mais do que um quinto desses constituído por falantes de iorubá. Eles vieram principalmente de Serra Leoa (onde escravos resgatados pela Marinha Inglesa tinham sido inicialmente registrados e depois realocados dentro da colônia), mas também de embarcaçôes britânicas que os transportaram a partir de Sta. Helena, Rio de Janeiro e Cuba. ${ }^{29} \mathrm{~A}$ maior realocação dentro da diáspora, ainda que menos mensurável, ocorreu antes que a escravidão tivesse acabado, quando os donos de plantaçôes se mudaram com seus escravos ou os enviaram para outras partes das Américas. O Caribe Francês, como vimos, recebeu o segundo maior contingente de escravos que falavam iorubá das Américas. Os plantadores franceses saíram das Pequenas Antilhas Francesas (French Lesser Antilles) com seus escravos na última parte do século dezoito para Trinidad, antes que essa se tivesse tornado britânica. Outros saíram de São Domengo para Louisiana e Cuba, tanto antes como depois do começo da mais bem sucedida revolta de escravos da história. Essa migração, tanto secundária (ocorrida no interior das Américas) como a de retorno para a África, foi freqüentemente dramática, mas é preciso aprendêla no contexto mais geral da diáspora. Certamente bem menos do que dez por cento daqueles mencionados na coluna 1 da tabela 5 se mudaram para regiões completamente novas, quer no Velho, quer no Novo Mundo, após sua migração inicial forçada. O retorno para a África aponta para as aspirações dos iorubás, mas não para a maioria deles, à realidade.

Finalmente, vale a pena notar que as línguas, e mais amplamente as culturas, de alguns grupos parecem migrar mais facilmente do que as de outros. Assim, enquanto que os falantes de alemão foram o maior grupo de europeus a migrar para a América do Norte do século dezoito (e, na verdade, ultrapassaram em número os falantes de iorubá, antes de 1808), seguidos por mais migrantes em meados do século dezenove, eles parecem ter se integrado na sociedade que os acolheu com grande rapidez, tendo, todavia, acrescentado poucos elementos da cultura "alemã" à sociedade 
estadunidense. No caso da migração compulsória africana, os iorubás foram dos últimos a chegar, mas não foram nem a população mais numerosa, nem a mais concentrada pelas Américas. Estimativas razoavelmente precisas para outros grupos eventualmente tornar-se-ão disponíveis, mas é provável que os ibos e alguns povos da África Central Atlântica foram mais numerosos e mais fortemente concentrados do que os iorubás - os ibos em partes do Caribe Britânico, e alguns dos chamados grupos congo no sudeste do Brasil. Ainda assim, o impacto dos falantes de iorubá nas sociedades coloniais que emergiram em muitas partes das Américas parece, aos acadêmicos modernos, ter sido forte e, à luz da evidência apresentada aqui, desproporcional em relação ao número relativo de chegadas iorubá. Enquanto que os "sobreviventes" ibos no Chesapeake receberam muita atenção, as comparações com os iorubás nas Américas como um todo indicam a relativa fraqueza das tradiçóes orais igbo, especificamente representadas em canções, rituais religiosos, histórias, provérbios etc. Nas plantaçóes do oeste de Cuba, em qualquer ano do século dezenove, os iorubás não tinham outra escolha a não ser mesclarem-se a grandes quantidades de Susus (de Serra Leoa/Guiné-Conakry), ibos (de toda a região que agora é o sudeste da Nigéria), yaos (do sudeste da África) e lundas (do Vale Kasai, em Angola). Nenhum desses grupos era numericamente dominante. A ilha, na verdade, recebeu a maior mistura de povos africanos do que qualquer outra região das Américas. Os cabildos de Havana e os rituais da Santería - seguida por grandes números de cubanos de origem africana - podem, ou não, ter sido imediatamente reconhecidos pelos povos Egba, Ijeba ou Ijesha, da África Ocidental, mas seria difícil encontrar muitas de suas raízes na África não-iorubá.

Em Trinidad ocorreu uma situação parecida, em uma escala muito menor. Os falantes de iorubá estavam, sem dúvida, representados nas companhias dos plantadores franceses, que chegaram a convite do governo colonial espanhol, antes que os britânicos tivessem conquistado aquelas regiōes. Os comerciantes escravagistas britânicos trouxeram mais falantes do iorubá imediatamente após a anexação britânica, à medida que eles retornavam à força para a Costa dos Escravos, logo após o fim do comércio de escravos francês, e um terceiro fluxo veio na forma de indentured workers de Serra Leoa. Apesar disso, fluxos muito maiores de escravos chegaram de outras partes do oeste e da região África Central Atlântica, enquanto que os números de iorubás entre os 13.984 escravos nascidos na 
África identificados no primeiro registro de escravos de Trinidad, em 1813, só pode ser descrito como minúsculo. ${ }^{30}$ Isto contrasta, estranhamente, com a grande presença iorubá detectada na língua, na religião e, na realdiade, nas comunidades, tanto urbana como rural, que foram identificadas como iorubás na última parte do século dezenove e na primeira parte do século vinte. ${ }^{31}$ Uma vez mais é difícil evitar a conclusão de que a influência iorubá foi desproporcional a seus números. Pode-se encontrar, nos registros europeus, todo tipo de comentário que se deseje sobre qualquer nação africana, mas a opinião de Verteuil, em 1858, teve eco em muitos relatórios europeus no século dezenove e também entre os vizinhos contemporâneos dos iorubás. Estes, disse ele,

se orientavam por um sentido de associação; e... o princípio de união para o bem comum foi amplamente posto em prática, onde quer que eles se fixassem, em quaisquer quantidade; em verdade, toda a raça iorubá pode ser considerada como formando uma espécie de liga social para ajuda mútua e proteção. ${ }^{32}$

$\mathrm{Na}$ Bahia, como já foi dito, os falantes iorubá compunham grande parte dos desembarques de africanas, mais do que os ocorridos em Cuba ou em Trinidad, mas ainda assim eram uma minoria. Independentemente de quaisquer incidentes espetaculares, como a rebeliāo dos escravos de 1835, na Bahia, onde os iorubás formaram mais de três quartos dos escravos levados ao tribunal, sua presença é mais forte e melhor documentada do que a de quaisquer outros povos africanos nas Américas. ${ }^{33}$ De todos os vínculos transatlânticos estabelecidos entre a África e as Américas durante a era do comércio de escravos, a ligação entre a Bahia e a Baía de Benin foi, provavelmente, a única que continuou na base de comércio, embora de valores muito reduzidos, quando o comércio escravagista propriamente dito foi suprimido. Um mercado para tecidos iorubá na Bahia continuou até a segunda metade do século dezenove, apesar da revolução na manufatura têxtil do Atlântico Norte.

Logicamente, o ambiente das Américas foi determinante na formação de todas as sociedades do Novo Mundo - de base européia ou africana. Mas o caso dos iorubás sugere que nem todas as culturas em jogo tiveram papéis proporcionais ao número de seus migrantes, na interação entre migrantes, ou na interação entre os migrantes e o meio-ambiente que resultou nas sociedades coloniais. Ao avaliar a crioulização, não se 
pode simplesmente confiar nos números relativos dos diferentes povos quer africanos, quer europeus -, da mesma forma que não se pode ignorar por completo a origem dos migrantes. Os historiadores deveriam talvez prestar mais atenção ao local de onde vieram estes migrantes, ao menos aqueles africanos submetidos. Ironicamente, dada a natureza desse ensaio, o tamanho e extensão de um grupo não é necessariamente um indicador confiável do seu impacto.

Tabela $1^{34}$ - Africanos originários da Baía de Benin e posteriormente libertados, de acordo com as regiões interioranas de origem (conforme os registros da Comissão Mista da Corte de Havana), 1826-1839

\begin{tabular}{|l|l|r|r|}
\hline $\begin{array}{l}\text { Região Interiorana } \\
\text { adjacente à B. de } \\
\text { Benin e Nação }\end{array}$ & Nome Atual & Número & Porcentagem \\
\hline Oeste & Allada & 142 & .05 \\
\hline Lucumi Arara & Popo & 317 & .10 \\
\hline Mina Popo & $?$ & 307 & .10 \\
\hline Mina & Fanti & 88 & .03 \\
\hline Mina JantiFanti & Allada & 41 & .01 \\
\hline Arara & Mahi* & 62 & .02 \\
\hline Magin & Allada & 77 & .03 \\
\hline Mago Arara & & 1034 & .34 \\
\hline Regional total & & 2 & .00 \\
\hline Norte & Fulani & 6 & .00 \\
\hline Mandinga Fula & Hausa & 22 & .01 \\
\hline Lucumi Jausa & Nupe & 1 & .00 \\
\hline Lucumi Tapa & Borgu & 1 & .00 \\
\hline Lucumi Bogu & Kakanda & 61 & .02 \\
\hline Lucumi Cacanda & Konkomba or Gurma & .03 \\
\hline Lucumi Chamba & Kong \\
\hline Regional total & & & \\
\hline
\end{tabular}


A Diáspora dos Falantes de Iorubá, 1650-1865: Dimensốes e ImPlicaÇốes • 291

\begin{tabular}{|l|l|r|r|}
\hline $\begin{array}{l}\text { Região Interiorana } \\
\text { adjacente à B. de } \\
\text { Benin e Nação }\end{array}$ & Nome Atual & Número & Porcentagem \\
\hline Iorubá & & & \\
\hline Lucumi Ello & Oió & 1236 & .41 \\
\hline Lucumi Aguia & $?$ & 23 & .01 \\
\hline Lucumi Efu & Efon/Ekiti & 1 & .00 \\
\hline Lucumi Eba & Egba & 58 & .02 \\
\hline Lucumi Llabu & Yagba or Ijebu? & 74 & .02 \\
\hline Lucumi Ecumacho & Ikumeso or Ekun Eso & 470 & .15 \\
\hline Lucumi Ota & Ota (Awori) & 49 & .00 \\
\hline Lucumi Yesa & Ijesha & 3 & .02 \\
\hline Lucumi Sabe & Sabe & 1 & .00 \\
\hline Regional Total & & 1915 & .63 \\
\hline Leste, não-iorubá & & & \\
\hline Carabali Oru & Oron & 3 & .00 \\
\hline Total regional & & 3 & .00 \\
\hline Total Geral Identificado & & 3645 & \\
\hline Não Identificado & & 582 & \\
\hline Lucumi & & 36 & \\
\hline $\begin{array}{l}\text { Todos os demais } \\
(16 \text { grupos) }\end{array}$ & & & \\
\hline Total & & & \\
\hline & & & \\
\hline
\end{tabular}

\footnotetext{
* Curtin, ...Census, 183, não relaciona "Magi" a "Mahi” e deixa o primeiro não identificado.
}

Fonte: Calculado do Public Record Office, Foreign Office, series 313 (FO 313), vols. 56-62. 
Tabela 2 - Africanos originários da Baía de Benin e posteriormente libertados de acordo com a região interiorana de origem e os portos de embarque (de acordo com os registros da Corte da Comissão Mista de Havana), 1826-1839

\begin{tabular}{|l|r|r|r|r|r|r|r|r|r|r|}
\hline $\begin{array}{l}\text { Portos de } \\
\text { Embarque }\end{array}$ & \multicolumn{2}{l|}{$\begin{array}{l}\text { Oeste, } \\
\text { não-iorubá }\end{array}$} & \multicolumn{2}{l|}{$\begin{array}{l}\text { Norte, } \\
\text { não-iorubá }\end{array}$} & \multicolumn{2}{l|}{$\begin{array}{l}\text { Leste, } \\
\text { não-iorubá }\end{array}$} & \multicolumn{2}{l|}{$\begin{array}{l}\text { lomente } \\
\text { iorubá }\end{array}$} & \multicolumn{2}{|l|}{ Total } \\
\hline & $\mathrm{N}^{\circ}$ & $\%$ & $\mathrm{~N}^{\circ}$ & $\%$ & $\mathrm{~N}^{\circ}$ & $\%$ & $\mathrm{~N}^{\circ}$ & $\%$ & $\mathrm{~N}^{\circ}$ & $\%$ \\
\cline { 2 - 14 } & 777 & 79.7 & 81 & 8.3 & 0 & 0 & 117 & 12.0 & 975 & 100 \\
\hline Popo & 269 & 18.2 & 12 & 0.8 & 1 & 0.1 & 1194 & 80.9 & 1476 & 100 \\
\hline Ljudá & 5 & 0.8 & 0 & 0 & 2 & 0.3 & 604 & 98.9 & 611 & 100 \\
\hline Lagos & 1051 & & 93 & & 3 & & 1915 & & 3062 & 100 \\
\hline
\end{tabular}

Fonte: Calculado da tabela 1. Os portos de embarque para as embarcações listadas em FO 313, vols. 56-62 foram identificados do TSTD.

Tabela 3 - Números estimados de escravos (em milhares) dos portos na Baía de Benin por quarto de século, 1650-1865

\begin{tabular}{|r|r|r|r|r|r|r|r|r|r|r|}
\hline & Popo & Ajudá & $\begin{array}{r}\text { Offra/ } \\
\text { Jaquim }\end{array}$ & Epe & $\begin{array}{r}\text { Porto } \\
\text { Novo }\end{array}$ & $\begin{array}{r}\text { Badagri// } \\
\text { Apa }\end{array}$ & $\begin{array}{r}\text { Lagos/ } \\
\text { Onim }\end{array}$ & Benin & $\begin{array}{c}\text { All } \\
\text { Other }\end{array}$ & Total \\
\hline $1651-1675$ & 0 & 1.0 & 20.9 & 0 & 0 & 0 & 0 & 0 & 0 & 21.9 \\
\hline $1676-1700$ & 2.7 & 133.4 & 85.9 & 0 & 0 & 0 & 0 & 0 & 0.9 & 222.9 \\
\hline $1701-1725$ & 1.8 & 374.4 & 28.6 & 0 & 0 & 0 & 0 & 1.2 & 1.6 & 407.5 \\
\hline $1726-1750$ & 43.8 & 177.9 & 21.2 & 36.0 & 0 & 15.3 & 0 & 10.9 & 1.0 & 306.2 \\
\hline $1751-1775$ & 20.1 & 130.4 & 0.6 & 17.2 & 11.7 & 32.8 & 3.6 & 36.2 & 0.3 & 253.0 \\
\hline $1776-1800$ & 15.0 & 78.3 & 5.6 & 0.5 & 96.8 & 18.1 & 24.0 & 25.1 & 0.9 & 264.4 \\
\hline $1801-1825$ & 7.2 & 72.5 & 0.9 & 0 & 19.2 & 14.1 & 114.2 & 4.6 & 4.7 & 236.6 \\
\hline $1826-1850$ & 11.9 & 82.9 & 1.9 & 0 & 7.7 & 5.2 & 170.6 & 1.2 & 6.8 & 288.4 \\
\hline $1851-1865$ & 1.1 & 24.7 & 0 & 0 & 0 & 0 & 4.9 & 0 & 7.0 & 37.7 \\
\hline $1651-1865$ & 103.6 & 1075.5 & 165.6 & 53.7 & 135.4 & 85.5 & 317.3 & 79.2 & 23.2 & 2039 \\
\hline
\end{tabular}

Notas* Como o porto de embarque foi freqüentemente denominado "Popo", essa coluna combina Pequeno Popo com Grande Popo, embora esses portos ficassem a 15 milhas um do outro. Para as viagens onde o prefixo foi dado, 95 por cento embarcaram seus escravos em Pequeno Popo.

Fonte: Eltis, Richarson, Behrendt, The Atlantic Slave Trade: A New Census.

TOPOI, v. 7, n. 13, jul.-dez. 2006, pp. 271-299. 


\section{Tabela 4 - Números estimados de partidas de escravos (em milhares) dos portos na Baía de Benin por períodos de cinco anos, 1751-1800}

\begin{tabular}{|l|r|r|r|r|r|r|r|r|r|}
\hline & Popo* $^{*}$ Ajudá & $\begin{array}{c}\text { Offra/ } \\
\text { Jaquim }\end{array}$ & $\begin{array}{c}\text { Porto } \\
\text { Novo }\end{array}$ & $\begin{array}{c}\text { Badagri } \\
\text { /Apa }\end{array}$ & $\begin{array}{c}\text { Lagos/ } \\
\text { Onim }\end{array}$ & Benin & Epe & Total \\
\hline $1751-1755$ & 4.0 & 28.1 & 0 & 0 & 8.4 & 0 & 1.8 & 8.6 & 50.9 \\
\hline $1756-1760$ & 9.0 & 21.7 & 0 & 0 & 0 & 0 & 7.2 & 0 & 37.9 \\
\hline $1761-1765$ & 4.8 & 30.0 & 0.6 & 1.6 & 4.1 & 0.6 & 10.1 & 0.9 & 52.7 \\
\hline $1766-1770$ & 3.7 & 21.7 & 0 & 5.6 & 2.7 & 1.0 & 11.3 & 4.5 & 50.5 \\
\hline $1771-1775$ & 2.2 & 29.8 & 0.6 & 4.4 & 13.1 & 2.0 & 9.4 & 0 & 61.5 \\
\hline $1776-1780$ & 3.2 & 18.8 & 1.6 & 17.8 & 6.8 & 1.8 & 3.2 & 0 & 53.2 \\
\hline $1781-1785$ & 1.0 & 21.7 & 2.5 & 8.0 & 2.7 & 3.2 & 5.0 & 0 & 44.1 \\
\hline $1786-1790$ & 0 & 12.1 & 0.9 & 33.9 & 3.3 & 8.4 & 7.4 & 0.3 & 66.3 \\
\hline $1791-1795$ & 11.5 & 16.5 & 0 & 11.8 & 1.9 & 6.6 & 2.2 & 0 & 50.5 \\
\hline $1796-1800$ & 4.6 & 15.5 & 0 & 15.3 & 1.4 & 3.3 & 0 & 0 & 40.1 \\
\hline $1751-1800$ & & & & & & & & & 507.7 \\
\hline
\end{tabular}

Notas: *Como o porto de embarque foi freqüentemente denominado "Popo", essa coluna combina Pequeno Popo com Grande Popo, embora esses portos ficassem a 15 milhas um do outro. Para as viagens onde o prefixo foi dado, 95 por cento embarcaram seus escravos em Pequeno Popo.

Fonte: Eltis, Richarson, Behrendt, The Atlantic Slave Trade: A New Census. 


\section{Tabela 5 - Séries ajustadas de partidas dos prisioneiros falantes de iorubá e seus destinos nas Américas, 1651-1865 (em milhares)}

\begin{tabular}{|c|r|c|c|c|c|c|c|c|}
\hline & $\begin{array}{c}N^{\circ} \\
\text { Estimado } \\
\text { de iorubás }\end{array}$ & $\begin{array}{c}\text { Grã-Bretanha, } \\
\text { América } \\
\text { do Norte }\end{array}$ & $\begin{array}{c}\text { Ilhas } \\
\text { Leeward } \\
\text { Britânicas }\end{array}$ & $\begin{array}{c}\text { Ilhas } \\
\text { Windward } \\
\text { Britânicas } \\
\text { +Trinidad }\end{array}$ & Jamaica & Barbados & Guianas & $\begin{array}{c}\text { Ilhas } \\
\text { Windward } \\
\text { Francesas }\end{array}$ \\
\hline $1651-1675$ & 2.2 & & & & & & & 2.2 \\
\hline $1676-1700$ & 22.2 & & 0.6 & & 4.4 & 7.6 & 0.7 & 0.7 \\
\hline $1701-1725$ & 41.7 & 0.5 & 0.8 & & 6.7 & 3.6 & 4.6 & 5.1 \\
\hline $1726-1750$ & 89.5 & 0.4 & 2.4 & & 4.1 & 2.2 & 9.8 & 25.2 \\
\hline $1751-1775$ & 140.1 & 2.6 & 1.6 & 2.2 & 20.0 & 2.0 & 2.1 & 8.0 \\
\hline $1776-1800$ & 172.9 & & 0.4 & 10.9 & 18.7 & 1.3 & 1.7 & 2.4 \\
\hline $1801-1825$ & 211.4 & 1.4 & & 3.6 & 5.9 & 1.5 & 7.1 & 1.0 \\
\hline $1826-1850$ & 257.4 & & & 2.8 & & 1.5 & 0.4 & 1.2 \\
\hline $1851-1865$ & 30.7 & & & & & & & \\
\hline All years & 968.1 & 4.9 & 5.8 & 19.5 & 59.8 & 19.7 & 26.4 & 45.8 \\
\hline
\end{tabular}

\section{Tabela 5 (cont) - Séries ajustadas de partidas dos prisioneiros falan- tes de iorubá e seus destinos nas Américas, 1651-1865 (em milhares)}

\begin{tabular}{|c|c|c|c|c|r|r|r|r|r|}
\hline & $\begin{array}{c}\text { S. } \\
\text { Domingo }\end{array}$ & $\begin{array}{c}\text { América } \\
\text { Espanhola }\end{array}$ & $\begin{array}{c}\text { Caribe } \\
\text { Espanhol }\end{array}$ & $\begin{array}{c}\text { Caribe } \\
\text { Holandês }\end{array}$ & $\begin{array}{c}\text { Nordeste } \\
\text { do Brasil }\end{array}$ & Bahia & $\begin{array}{c}\text { Sudeste } \\
\text { do Brasil }\end{array}$ & $\begin{array}{c}\text { Outras } \\
\text { Américas }\end{array}$ & África \\
\hline $1651-1675$ & & & & & & & & & \\
\hline $1676-1700$ & & 0.3 & & 1.4 & & 4.8 & & 1.6 & \\
\hline $1701-1725$ & 6.3 & 1.5 & 0.1 & 3.0 & 0.1 & 9.1 & 0.1 & 0.1 & \\
\hline $1726-1750$ & 39.0 & & 0.3 & 0.9 & 0.7 & 4.7 & & 0.5 & \\
\hline $1751-1775$ & 49.8 & & 0.3 & 0.4 & 0.7 & 50.6 & & 0.3 & \\
\hline $1776-1800$ & 54.7 & & 2.9 & & & 79.3 & & 0.2 & \\
\hline $1801-1825$ & & 0.7 & 5.6 & & 3.8 & 175.2 & 977 & & 7.8 \\
\hline $1826-1850$ & & & 65.6 & & 1.7 & 116.2 & 28.4 & 5.4 & 32.4 \\
\hline $1851-1865$ & & & 25.0 & & & & 2.2 & & 1.8 \\
\hline All years & 149.8 & 2.5 & 99.8 & 5.7 & 7.0 & 439.9 & 31.7 & 8.1 & 42.0 \\
\hline
\end{tabular}

Fonte:

Notas: O autor está agradecido a Stanley L. Engerman, Paul Lovejoy, Ugo Nwokeji, Philip Morgan e David Richardson, bem como aos participantes do Johns Hopkins' History Seminar (Seminário Johns Hopkins de História), em novembro de 2002, e ao Columbia Seminar on Atlantic History (Seminário da Universidade de Colúmbia sobre a História do Atlântico), realizado em SUNY Stony Book, em fevereiro de 2003, pelos comentários feitos a respeito de versões anteriores deste ensaio. 


\section{Notas}

${ }^{1}$ Robin Law, Ethnicity and the Slave Trade: "Lucumi" and "Nago" as Ethonyms in West Africa, History in Africa, 24 (1997): 205-19.

${ }^{2}$ Ver Marianne Wokeck, Irish and German Migration to Eighteenth Century North America, in David Eltis (org.), Coerced and Free Migration: Global Perspectives (Stanford, 2002: 176-203, e a literatura lá citada.

${ }^{3}$ Robin Law, "Ethnicity and the Slave Trade: "Lucumi" and "Nago" as Ethonyms in West Africa," History in Africa, 24 (1997): 205-19.

${ }^{4}$ Ver Marianne Wokeck, "Irish and German Migration to Eighteenth Century North America," in David Eltis (org.), Coerced and Free Migration: Global Perspectives (Stanford, 20020: 176-203, e a literatura lá citada.

${ }^{5}$ Este procedimento é baseado em estimativas da distribuição de escravos, feitas por grupamentos nacionais de navios da Europa e das Américas, referentes a oito regiōes africanas costeiras. As estimativas não são apresentadas aqui, mas são fáceis de ser obtidas para qualquer período, após 1675, de David Eltis, Stephen Behrendt, David Richardson e Herbert S. Klein, The Transatlantic Slave Trade: A Database on CD-ROM (Cambridge, 1999), de agora em diante, simplesmente mencionado como TSTD.

${ }^{6} \mathrm{Nem}$ todos os navios negreiros conseguiram chegar às Américas, ou à África. Felizmente, há bastante informaçôes disponíveis sobre o resultado final da viagem, na medida em que em quase noventa por cento das viagens sabemos se o navio embarcou escravos, enquanto que, em pouco mais de noventa por cento, sabemos se o navio chegou à África antes de iniciar o comércio. No todo, quase uma viagem em dez incluída no presente cálculo não trazia os escravos para as Américas e somente 82 por cento de todos os navios conseguiam entregar os escravos sob o controle de seus donos originais.

${ }^{7}$ Os registros de Havana estão no Departamento de Registro Público (British Public Record Office), FO 313, vols. 56-62. Para consultar o que parece ser o único uso deste material, ver Roseanne Marion Adderley, 'New Negroes from Africa': Culture and Community Among Liberated Africans in the Bahamas and Trinidad 1810-1900. Dissertação de Doutorado Inédita, Universidade da Pensilvânia (University of Pennsylvania), 1996. Os registros de Serra Leoa (na série FO84) foram usados em R. Meyer-Heiselberg, Notes from the Liberated African Department in the Archives at Fourah Bay College (Notas do Departamento Africano Liberado), Freetown, Serra Leoa (Uppsala, 1967); David Northrup, Trade Without Rulers: Precolonial Economic Development in Southeastern Nigeria (Oxford, 1978), 58-65, 231; David Eltis, Welfare Trends Among the Yoruba at the Beginning of the Nineteenth Century: the Anthropometric Evidence, Journal of Economic History, L (1990), 521-40; e idem, Nutritional Trends in Africa and the Americas: Heights of Africans, 18191839, Journal of Interdisciplinary History, XII (1982), 453-75. G. Ugo Nwokeji and David Eltis, The Roots of the African Diaspora: Methodological Considerations in the Analysis of Names in the Liberated African Registers of Serra Leoa and Havana, History in Africa, 29 (2002): 365-79; e idem, Characteristics of Captives Leaving the Cameroons for the Americas, 1822-1837, Journal of African History, 43 (2002): 191-210.

TOPOI, v. 7, n. 13, jul.-dez. 2006, pp. 271-299. 
${ }^{8}$ Os registros distinguem, por um lado, entre "incisões", "cortes”, "marcas", "tatuagens", que consideramos como evidência de procedimentos de cicatrização voluntária, e, por outro lado, "cicatrizes" propriamente ditas. Cicatrizes são provavelmente o resultado de atividade involuntária. A maior parte dessas últimas teria pouco significado cultural.

${ }^{9}$ Um exemplo menor é o nome dos réus nos procedimentos da corte, após a revolta de 1835 na Bahia. Ver Joao Reis, Slave Rebellion in Brazil: The Muslim Uprising of 1835 in Bahia (Baltimore, 1993), pp. 155-56.

${ }^{10}$ Deveria ser enfatizado que a ligação de nomes com etnicidade não tem implicações necessárias para a definição de etnicidade por si só. Para uma discussão desta questão, ver Nwokeji e Eltis, Characteristics, 191-2.

${ }^{11}$ TSTD.

${ }^{12} \mathrm{O}$ segundo maior grupo de iorubás na tabela 1 é Ecumacho, que não tem contrapartida moderna. Ojo Olatunji da Universidade de York sugeriu que este é Ikumeso ou Ekun Eso. - em iorubá, 'a província do valente'. Eso é o título de uma elite militar de Oió que foi retirada da Província Oriental do reino. Os nomes de pessoas neste grupo são principalmente iorubás, de qualquer maneira.

${ }^{13}$ A maior parte das embarcações era capturada nas Américas, em vez de na África, de modo que a determinação da localização dos portos africanos e, talvez, da etnicidade dos capturados deve ter sido feita de forma quase aleatória .

${ }^{14}$ Quantidade calculada multiplicando-se os 162.800 escravos que deixaram a Baía de Benin entre 1826 e 1840 (Eltis, Behrendt e Richardson, Census, no prelo) por .625 (a parte de todos os cativos identificados que eram iorubás, da tabela 1). Enquanto que o volume estimado geral da Baía de Benin usado aqui é para quinze anos, uns poucos iorubás saíram de portos na Baía de Biafra e não são, portanto, incluídos na estimativa da Baía de Benin. A tendência ascendente que inclui o ano extra é compensada pela tendência descendente da omissão dos iorubás que partiram de outros portos distintos da Baía de Benin.

${ }^{15}$ A.F.C. Ryder, Benin and the Europeans, 1485-1897 (Londres, 1969), pp. 197-98.

${ }^{16}$ Robin Law, A Lagoonside Port on the Eighteenth Century Slave Coast; Caroline SorensenGilmour, Slave-Trading along the Lagoons of South-West Nigeria: The Case of Badagry em Robin Law e Silke Strickrodt (orgs.), Ports of the Slave Trade (Bights of Benin and Biafra (Stirling, 1999), págs. 85-6.

${ }^{17}$ Este parágrafo e o próximo são basedos em David Eltis, Economic Growth and the Ending of the Transatlantic Slave Trade (New York, 1987), pp. 168-69.

${ }^{18}$ Para o tráfico de escravos em Lagos, cerca de 1840, ver Kristin Mann, The Birth of African City: trade, State and Emancipation in Nineteenth Century Lagos (forthcoming, chapters 1 and 2). A correspondência do Rei Kosoko, aprisionado pelos britânicos e publicada verbatim na Publicação Sessional Papers da Câmara dos Lordes, 1852-53, 22: 327-66, mostra o Rei vendendo escravos em comissão na Bahia, mas isso dá conta de menos de dez por cento de todos os escravos vendidos em 1848 e 1849 . Kosoko também mandou construir seu próprio navio de escravos na Bahia. Ver também os anexos em $\mathrm{H}$.

TOPOI, v. 7, n. 13, jul.-dez. 2006, pp. 271-299. 
Wise para Calhoun, Nov 1, 1844, Congresso dos Estados Unidos, H. Exec Doc. no. 148, 28-2, pp. 44-47. Para Ajudá, ver Robin Law, Royal Monopoly and private Enterprise: The Case of Dahomey. The Journal of African History 18 (1977): 559-71; e Slave-Raiders and Middlemen, Monopolists and Free Traders: The Supply of Slaves for the Atlantic Trade in Dahomey, c. 1715-1850, ibid, 30 (1989): 45-68.

${ }^{20}$ A evidência está resumida e discutida em Robin Law, The Slave Coast of West Africa, 1550-1750 (Oxford, 1991), 186-191; idem, Ethnicity and the Slave Trade, (Etnicidade e o Comércio de Escravos) 205-19, especialmente 207.

${ }^{21}$ Law, Ethnicity and the Slave Trade, (Etnicidade e o Comércio de Escravos)207; idem, The Kingdom of Allada, 101-104; Paul E. Lovejoy e David Richardson, The Yoruba Factor in the Atlantic Slave Trade, (artigo não publicado).

${ }^{22}$ Law, The Slave Coast, 309-14; idem, A Lagoonside Port on the Eighteenth Century Slave Coast: The Early History of Badagri, Canadian Journal of African Studies, 28 (1994): 32-59.

${ }^{23}$ Pierre Verger, Trade Relations Between the Bight of Benin and Bahia, 17th-19th Century, traduzido por Evelyn Crawford(Ibadan, 1976), págs., 1-7. (a citação está na pág. 7). Para St. Domingue ver Geggus, Sex Ratio, Age and Ethnicity in the Atlantic Slave Trade 32-33. Eltis, Economic Growth, 169-70.

${ }^{24}$ Poder-se-ia argumentar a favor da inclusão de Porto Novo no grupo oriental para essa avaliação. No entanto, qualquer tendência resultante da decisão de manter Porto Novo no grupo de portos centrais é compensada pela inclusão de Benin no grupo oriental. Benin, o principal porto oriental de comércio entre 1726 e 1775, teria enviado altos números de Edos, povos do Delta ocidental, bem como outros falantes não-iorubá para o tráfico, embora haja falta de evidência sobre a etnicidade dos presos que deixaram Benin antes de 1770.

${ }^{26}$ Ver Capítulo 3 de David Eltis, David Richardson e Stephen Behrendt, The Atlantic Slave Trade: A New Census (Cambridge University Press, no prelo).

${ }^{27}$ Os portugueses e os britânicos chegaram perto disso, antes de 1850, mas cada um desses países despachou, talvez, somente dois terços do número total de iorubás (ver David Eltis, Free and Coerced Migrations from the Old World to the New, in Eltis (org.), Coerced and Free Migration, págs. 62-63).

${ }^{28}$ Mesmo aqui, evidência tirada de registros de sucessões de Salvador, a maior cidade na província da Bahia, indica uma proporção muito menor de iorubás - somente um quinto. Ver Reis, Slave Rebellion in Brazil, 140.

${ }^{29}$ Essas proporções são derivadas, comparando-se a coluna 1 da tabela 5 com estimativas das partidas totais das diferentes regiōes nas Américas em Eltis, Richardson e Behrendt, ... Census. Para confirmação dos pequenos números de iorubás no Caribe Britânico, ver análise dos dados de registros de escravos, de Barry Higman, em Slave Populations of the British Caribbean, 1807-1834 (Baltimore, 1987), págs. 442-58. Uma estimativa alternativa, baseada nos registros de sucessão de Salvador, a maior cidade na província da Bahia, indica uma porcentagem muito menor de iorubás do que está sendo sugerido aqui somente um quinto. Ver Reis, Slave Rebellion in Brazil, 140. 
${ }^{30}$ Jean Herskovits Kopytoff, A Preface to Modern Nigeria: The "Serra Leoaians" in Yoruba, 1830-1890 (Madison, Wisc., 1965), especiamente, 44-60; Rudolfo Sarracino, Los que Volvieron a Africa (Havana, 1988), págs. 47-124. Fontes britânicas, especialmente, FO 84 no Public Record Office/Escritório de Registro Público, tem muito material sobre esse assunto que ainda tem de ser examinado - incluindo o extraordinário caso de "San Antonio" (identificação de viagem 3456, no TSTD) que em 1844 levou africanos pagantes que desejavam retornar às vizinhas de Lagos, em sua viagem à África, antes de tentar retornar a Cuba com escravos.

${ }^{31}$ Johnson U Asiegbu, Slavery and The Politics of Liberation 1787-1861; A Study of Liberated African Emigration and British Anti-Slavery Policy (Nova Iorque, 1969); David Northrup, Indentured Labor in The Age of Imperialism, 1834-1922 (Cambridge, 1995); Monica Schuler, "Alas, Alas, Kongo": A Social History of Indentured African Immigration into Jamaica, 1841-1865 (Baltimore, 1980).

${ }^{32}$ Higman, Slave Populations, 449.

${ }^{33}$ Maureen Warner-Lewis, Trinidad Yoruba: A Language of Exile) International Journal of the Sociology of Language, 83 (1990): 9-20; idem, Trinidad Yoruba: From Mother Tongue to Memory (Tuscaloosa, 1996). Para padrōes semelhantes nas Guianas e Belize, ver James Adeyinka Olawaiye, Yoruba religious and social traditions in Ekiti, Nigeria and three Caribbean countries: Trinidad-Tobago, Guyana and Belize.

${ }^{34}$ Louis Antoine Aimé de Verteuil, Three Essays on the Cultivation of Sugar Cane in Trinidad (Port of Spain, 1858), 175, citado em Warner-Lewis, Trinidad Yoruba, 44.

${ }^{35}$ Reis, Slave Rebellion in Brazil, 140; Verger, Trade Relations Between the Bight of Benin and Bahia.

${ }^{36}$ As fontes básicas usadas na identificação dos termos étnicos são D.H. Crozier and R.M. Blench, An Index of Nigerian Languages, 2d ed. (Dallas, 1992); Philip D. Curtin, The Atlantic Slave Trade: A Census (Madison, 1969); Robert S. Smith, Kingdoms of the Yoruba, 3d ed. (Madison, 1988). Oscar Grandio, Paul Lovejoy e Ojo Olatunji, todos da York University (Universidade de York), orientaram-me por território desconhecido.

\section{RESUMO}

O objetivo geral do artigo é propor uma análise quantitativa da etnicidade Iorubá, em suas expressóes na diáspora, uma vez que esse grupo não existia inicialmente como um povo, ou etnia, consciente de si mesmo. Trata-se de explorar em que medida as condiçôes criadas no Novo Mundo pelo tráfico de escravos pôde acelerar a constante renovação da formação identitária dos Iorubás. Para tanto, pretende-se apresentar uma estimativa mais sistemática do envolvimento dos Iorubás na dinâmica do tráfico e explorar as implicaçôes dessas descobertas para iluminar questóes mais amplas do repovoamento das Américas.

Palavras-chave: escravidão, Iorubá, etnicidade, análise quantitativa. 
A Diáspora dos Falantes de Iorubâ, 1650-1865: Dimensốes e ImplicaÇôes • 299

\section{ABSTRACT}

The article is a quantitative analysis of Ioruba ethnicity as expressed in the Diaspora. Initially, the Iorubá did not exist as a distinct people, ethnic group or cultural consciousness. The analysis intends to explore to what degree conditions created by the traffic of east African slaves to the New World accelerated the development of a permanent Iorubás' identity. It is intended to present a more systematic estimate of Ioruba involvement in the dynamics of slave trafficing, to explore the implications of these discoveries, and to illuminate broader questions concerning the re-peopling of the Americas.

Key-words: slavery, Iorubá, etnicity, quantitative analysis.

(recebido em março de 2006 e aprovado no mesmo mês) 